\title{
Ernest Pépin, Le Soleil pleurait
}

\section{Emanuela Cacchioli}

\section{Q OpenEdition}

\section{Journals}

\section{Édition électronique}

URL : https://journals.openedition.org/studifrancesi/4850

DOI : 10.4000/studifrancesi.4850

ISSN : 2427-5856

\section{Éditeur}

Rosenberg \& Sellier

\section{Édition imprimée}

Date de publication : 1 avril 2012

ISSN : 0039-2944

\section{Référence électronique}

Emanuela Cacchioli, «Ernest Pépin, Le Soleil pleurait », Studi Francesi [En ligne], 166 (I | LVI) | 2012, mis en ligne le 30 novembre 2015, consulté le 19 novembre 2021. URL : http://journals.openedition.org/ studifrancesi/4850; DOI : https://doi.org/10.4000/studifrancesi.4850

Ce document a été généré automatiquement le 19 novembre 2021.

\section{(c) (i) (9)}

Studi Francesi è distribuita con Licenza Creative Commons Attribuzione - Non commerciale - Non opere derivate 4.0 Internazionale. 


\title{
Ernest Pépin, Le Soleil pleurait
}

\author{
Emanuela Cacchioli
}

\section{RÉFÉRENCE}

ERNEST PÉPIN, Le Soleil pleurait, La Roque d'Anthéron, Vents d'Ailleurs, 2011, pp. 144.

Défini depuis toujours comme un «chef d'orchestre de la parole», Ernest Pépin ne se démentit pas avec son dernier roman Le Soleil pleurait. Pépin, qui compte parmi les plus grands écrivains de la Caraïbe, nous fait cadeau d'une œuvre très originale qui mêle le récit tragique d'une mulâtresse kidnappée à la beauté de la poésie et à la fierté d'un peuple qui, malgré tous les malheurs qu'il vit, s'obstine à résister et à se battre. Le résultat est un texte qui révèle la complexité sociale, politique et culturelle du monde caribéen. Bien que guadeloupéen, Pépin délaisse sa terre natale pour explorer Haïti et pour mettre en relief l'imaginaire commun des îles. Le prétexte de cette enquête naît d'un événement inhumain, c'est-à-dire l'enlèvement de Régina, une jeune fille qui a la «faute» d'avoir le teint clair et qui est, donc, pour ses ravisseurs, la fille d'un blanc très riche. Cependant le cliché n'est pas respecté parce que Régina vit avec sa mère MarieSoleil, une marchande qui s'est efforcée d'offrir à sa fille une vie bien meilleure que la sienne. Sur l'identité du père de Régina, le mystère est total. Bien qu'elle ait grandi avec Fanfan, le mari de sa mère, qui l'a toujours considérée comme son propre enfant, tout le monde fait semblant de ne rien savoir sur le sort de son père biologique. Marie-Soleil, qui est avec Régina la véritable héroïne du roman, commence sa bataille pour sauver la vie de sa fille et pour trouver la somme astronomique que les ravisseurs lui demandent. Une entreprise qui est vouée à l'échec dès le début, mais qui permet de sonder la société haïtienne et de raconter une force vitale à même de surmonter la mort et les désolations d'un quotidien qui est toujours affecté par des dynamiques supérieures et incompréhensibles pour les êtres communs. Toutefois, il faut remarquer qu'au centre $\mathrm{du}$ récit on trouve le personnage du conteur qui écoute et cherche à comprendre Marie-Soleil et qui se charge de diffuser l'histoire de Régina afin d'empêcher l'oubli. Voilà l'aspect le plus original du roman: le narrateur est le porte-parole du "poids» du malheur des deux femmes; il renoue les liens brisés du récit, il cherche des réponses 
pour éclairer les événements inexplicables, il lui «faut piéter des mangroves de choses non dites. Récolter des bribes. Imaginer l'insondable et plonger dans des trous opaques. Il [lui] faut emboîter des paroles rapportées» (p. 32). Se caractérisant comme une conscience extérieure qui veille sur les personnages féminins, il donne «mots» aux pensées de Marie-Soleil et il nous relate les sensations physiques et mentales que Régina éprouve à l'intérieur de sa prison. Au fur et à mesure que l'histoire se déroule, le raconteur se révèle comme «un assemblage de mots. Une machine qui parle toute seule pour meubler le silence de la mort» (p.132). C'est lui qui nous fait découvrir la poésie quand il dit: «Je suis la nuit quand elle délire, le soleil quand il pleure et la pluie quand elle tisse la vie» (p. 132) et qui nous fait aimer un pays fascinant et aux mille aspects puisqu'il sait que les mots sont toujours liés aux sentiments. Le lecteur peut donc savourer un texte qui est très proche de la prose poétique et qui avance par images suggestives, par listes, par mots et par expressions créoles, par une versification qui est propre d'un poème, mais qui suscite une profonde réflexion. Ce sont la parole et la poésie qui ont le pouvoir de sauver Marie-Soleil et le pays d'Haïti, mais aussi d'émouvoir et de fasciner le lecteur, comme toute la littérature que les îles de la Caraïbe ont produite. Pépin nomme Davertige de façon explicite, mais on trouve plusieurs citations «cachées» d'écrivains et de musiciens. L'enquête sur le passé de Marie-Soleil conduit le conteur au village de Paulette où l'on découvre une humanité méfiante qui refuse de se raconter aux étrangers. On constate aussi un contraste total avec le chaos engourdissant de Port-au-Prince, une véritable «chaudière d'un volcan» (p. 82), une ville qui s'est développée de façon anarchique et qui accueille toutes les formes humaines de survie face à un état prédateur. À l'intérieur de cette société, il ne reste que donner la parole aux femmes, c'est-à-dire aux êtres qui cachent le secret de la vie, qui se chargent du poids de la souffrance et qui ne renoncent jamais à se battre. Ce sont elles qui se lient à la mémoire coloniale et qui paient le prix de son héritage. En effet, on a l'impression que la prison de Régina est une représentation de la cale, synonyme d'exploitation et d'esclavage. Et si le contraste entre l'homme - qui garde l'illusion de la puissance - et la femme - qui résiste et se bat sans cesse - montre une supériorité féminine, on remarque que le malentendu entre les êtres empêche des résolutions définitives et la société haïtienne reste prisonnière des relations internationales, du passé colonial, du racisme, de la perversion politique qui affecte le peuple. Une purification temporaire est possible, mais la nature humaine a tendance à tomber toujours dans les mêmes erreurs.

2 Ce roman, où Ernest Pépin utilise les instruments narratifs qu'offre le «réalisme merveilleux», assure une lecture très agréable et est un outil de réflexion très puissant sur le monde caribéen. 